\title{
Luis Cernuda y Friedrich Hölderlin: la mitología griega como cosmovisión
}

\author{
JAVIER ADRADA DE LA TORRE \\ Universidad Autónoma de Madrid
}

Resumen: Este artículo analiza la presencia de la mitología griega en la poesía de Luis Cernuda, una cosmovisión que el sevillano tomó del romántico alemán Friedrich Hölderlin, a quien había leído y hasta traducido. En primer lugar, estudiaremos cómo el paganismo se plasma en los versos de Cernuda y en su manera de concebir el mundo y la escritura. A continuación, abordaremos el tema desde una perspectiva diacrónica: cómo el helenismo irrumpe en La Realidad y el Deseo y cómo se desvanece paulatinamente. Cuando sea conveniente, señalaremos semejanzas entre la propuesta poética de Hölderlin y la de Cernuda.

Palabras clave: mitología, paganismo, helenismo, Cernuda, Hölderlin.

Luis Cernuda and Friedrich Hölderlin: the Greek mythology as cosmovision

Abstract: This article analyses the presence of Greek mythology in the poetry of Luis Cernuda, a cosmovision that the Sevillian took from the German romantic Friedrich Hölderlin, whom he had read and even translated. Firstly, we will study the way paganism is reflected in Cernuda's verses and in his conception of world and writing. After that, we will approach the matter from a diachronic perspective, that is to say, how Hellenism turns up in La Realidad y el Deseo and how it gradually fades away. When needed, we will establish parallelisms between Hölderlin's poetic thought and that of Cernuda.

Keywords: mythology, paganism, Hellenism, Cernuda, Hölderlin. 


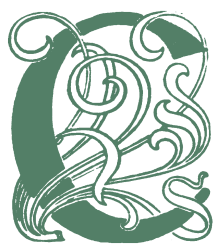

uenta Luis Cernuda, en su Historial de un libro, que fue hacia 1934 cuando empezó a escribir los primeros poemas de Invocaciones. Esta obra es un punto de inflexión en su evolución poética, porque actúa como bisagra entre la poesía de su etapa juvenil y sus escritos de madurez. Ello se debe a dos aspectos cruciales: en primer lugar, que se había «cansado de la estrechez [...] de los superrealistas» y de «los poemitas breves a la manera de Machado y Jiménez», porque no le bastaban para expresar su nuevo estado de conciencia; en segundo, que por aquellas fechas había empezado a leer a un poeta romántico alemán, Friedrich Hölderlin.

Así lo ratifica el propio Cernuda: «Más que mediada ya la colección [Invocaciones], antes de componer el 'Himno a la Tristeza', comencé a leer y a estudiar a Hölderlin, cuyo conocimiento ha sido una de mis mayores experiencias en cuanto poeta» (2000: 398). Pero la lectura y el estudio a los que se refiere el sevillano no le parecieron suficiente, de modo que se propuso traducir al poeta germano. Para entonces, ya era consabida su faceta como traductor de poesía francesa - Eluard y Nerval, concretamente-, pero en esta ocasión probó fortuna con una lengua que apenas conocía, lo cual delata el especial interés de Cernuda por Hölderlin.

Dado este impedimento, tuvo que servirse de la ayuda de un poeta y filósofo alemán que vivía por entonces en Madrid: Hans Gebser, quien trabajaba en una antología de poesía española contemporánea junto con el inglés Roy Hewin Winstone, amigo de Cernuda. Así pues, el sevillano y el alemán traducirían conjuntamente un total de dieciocho poemas de Hölderlin - más tres inéditos - , que acabarían publicados en la revista Cruz y Raya, dirigida por José Bergamín, en noviembre de 1935, junto con una nota introductoria redactada por el propio Cernuda. Aunque el sevillano se percató de algún error de traducción en aquella primera versión - reconocido por él mismo en Historial de un libro - , Bergamín no le brindó la oportunidad de enmendarlo en la edición que la editorial Séneca hizo en México en 1942.

En La Realidad y el Deseo fue trascendental el descubrimiento de Hölderlin, «que para Cernuda era, no sin razón, algo así como la personificación del romanticismo» (Peregrín Otero, 2004: 379). El sevillano halló en el alemán una nueva forma de concebir el mundo y la poesía: Hölderlin rechazaba el monoteísmo y evocaba el espíritu olvidado de las divinidades griegas; asimismo, 
consideraba que el poeta era el elegido por los dioses y que, por tanto, la poesía era un regalo de los cielos. Como aprecia Pujante (2004), «Cernuda se identificó con el Hölderlin que opone la hermosura de la naturaleza a la horrible vulgaridad humana; [...] que comprende la eternidad de los mitos paganos, donde se simbolizan el amor, la belleza, la poesía [...]; se identificó con el Hölderlin tocado por la mano de los dioses». Cernuda heredará esta cosmovisión durante el resto de su obra y tratará de aliviar en ella su incomprensión y su soledad.

Examinemos, para empezar, el siguiente pasaje de la nota introductoria a la traducción conjunta de Cernuda y Gebser:

Siempre extrañará a alguno la hermosa diversidad de la naturaleza y la horrible vulgaridad del hombre. Y siempre la naturaleza, a pesar de esto, parece reclamar la presencia de un ser hermoso y distinto entre sus perennes gracias inconscientes. De ahí la recóndita eternidad de los mitos paganos, que de manera tan perfecta respondieron a ese tácito deseo de la tierra con sus símbolos religiosos, divinos y humanizados a un tiempo mismo. (Cernuda, 1935: 115)

Este fragmento propone una antítesis y, seguidamente, ofrece una solución para la misma: primero, contrapone la belleza natural y la sordidez humana; a continuación, señala que el medio con el que reconciliar naturaleza y humanidad no es otro que el paganismo. Este será el eje de nuestro análisis en las próximas páginas: cómo la mitología helénica posibilita la armonía entre conceptos antagónicos, y cómo este fenómeno se aprecia en La Realidad y el Deseo.

Con Hölderlin, Cernuda consolida, como él mismo señala en Historial de un libro, «una nueva visión del mundo» (2000: 398), a saber, una visión mitológica. Así es, la mitología griega es capaz de explicar los misterios del mundo desde una perspectiva sobrenatural pero, a la vez, humana; los dioses paganos, aunque ya olvidados, representan la hermosura y la magia que se contrapone al vicario prosaísmo de la realidad física. Así lo considera Bruton (1984: 38-40):

Cernuda creates figures who bridge the divide between humanity and divinity by at the same time displaying the physical flesh of man and the numinous aura of a god. It is the response of poetry to the inadequacy 
of the world to provide such figures. [...] With this symbolism the myths united the world of men, of «vana apariencia», with the world of the gods, of «verdad».

Resultan significativos los dos términos de los que se sirve Bruton: por un lado, el de vana apariencia, con el que se refiere a la realidad mundanal que tanto repugna al poeta; por otro, el de verdad, concepto recurrente en la obra previa de Cernuda y que constituye la alternativa esencial a la apariencia meramente física. Las figuras que el sevillano recrea en sus poemas son, en efecto, individuos ambivalentes, a caballo entre la realidad material y la divina (sirvan como claro ejemplo «A un muchacho andaluz» $\mathrm{O}$ «El joven marino»).

Siguiendo en esta línea, es necesario destacar que la cosmovisión politeísta conjuga lo humano y lo divino en lugar de contraponerlo. Quizás este sea uno de los aspectos más importantes del paganismo y de su influencia en las ideas cernudianas: la comunión entre la naturaleza terrestre y la celestial. Frente a la concepción cristiana de la distancia entre Dios y el hombre, la mitología griega disipaba esta frontera y fusionaba ambas dimensiones en una sola.

Para percatarse de esta doble naturaleza basta con atender a la caracterización de los antiguos dioses griegos - aplicable, posteriormente, a los romanos - : la mayoría de ellos antropomórficos, llevados por pasiones tan incontrolables como las del hombre, capaces de procrear con seres humanos y de engendrar semidioses. En términos semejantes los define Cernuda: «blancos seres inmateriales impulsados por deseos no ajenos a la tierra, pero dotados de vida inmortal» (1935: 115); también lo hace Schiller en «Los dioses de Grecia»: «como todavía eran los dioses más humanos, / los humanos eran más divinos» ${ }^{1}$.

Este mestizaje y esta atribución de vicios terrenales es inconcebible si pensamos en Dios, perfecto en grado sumo, pletórico de virtudes. Si bien es cierto que Cristo, como encarnación de su abstracto Padre, sí recibió una forma humana, no fue víctima de los celos de Hera, ni del alcoholismo de Dioniso,

1 La traducción es mía. He aquí el texto original: «Da die Götter menschlicher noch waren, / waren Menschen göttlicher». Este poema de Schiller («Die Götter Griechenlandes») lo cita el propio Cernuda en "Juan Ramón Jiménez», un texto que publica en 1942 en el Bulletin of Spanish Studies de Liverpool (Cernuda, 1970: 193); de ahí su relevancia. 
ni de la promiscuidad de gran parte del Olimpo: el enviado de Dios fue ejemplo de mesura, de castidad y de decencia. Según Pujante (2004), esta confrontación alcanzaba dimensiones aún mayores en Cernuda, quien «se identificó con el paganismo helénico que [...] entroncaba con el rechazo de la moral judeocristiana que inculpaba su homoerotismo» o, podríamos sostener, sus placeres en general.

En «El poeta y los mitos», poema en prosa de Ocnos, encontramos declaraciones muy reveladoras con respecto a este asunto:

Bien temprano en la vida [...] cayó en tus manos un libro de mitología. Aquellas páginas te revelaron un mundo donde la poesía, vivificándolo como la llama al leño, transmutaba lo real. Qué triste te pareció entonces tu propia religión. [...] ¿Por qué te enseñaba a doblegar la cabeza ante el sufrimiento divinizado, cuando en otro tiempo los hombres fueron tan felices como para adorar, en su plenitud trágica, la hermosura? [...] cualquier aspiración que haya en ti hacia la poesía, aquellos mitos helénicos fueron quienes la provocaron y la orientaron.

Una vez más, Cernuda contrapone los valores católicos y los helénicos: frente al «sufrimiento divinizado» de aquellos, prefirió el culto a la hermosura de estos. Se trata de una tendencia que debió de brotar en él de niño y que, con Hölderlin, cristalizó en las creencias mitológicas de Invocaciones. Y uno de los aspectos más atractivos del paganismo griego era, precisamente, que no existía un divorcio insalvable entre lo celestial y lo mundano.

Seguramente a eso se refería Cernuda con «símbolos religiosos, divinos y humanizados a un tiempo mismo»: aunque las deidades griegas gozaran de una evidente condición deífica, no dejaban de reflejar los defectos y los apetitos propios de los hombres, quienes, al fin y al cabo, habían inventado a los dioses y los habían cortado a su medida. Además, como ya hemos indicado, existían las figuras de los semidioses, que conferían a los seres humanos rasgos divinos y, en consecuencia, estrechaban aún más los vínculos entre el orbe y el panteón.

Pues bien, he aquí la clave de la nueva poética que Cernuda adoptará en Invocaciones: la comunión entre lo humano y lo divino, entre la realidad y el deseo. Efectivamente, la que hasta ahora había sido una encarnizada dialéctica entre la hostil realidad y el cohibido deseo se convierte, con el hallazgo 
de la mitología, en una posible reconciliación. El mundo no es tan terrible si, más allá de su material prosaísmo, el poeta cree fervientemente en la existencia de fuerzas sobrenaturales que velan por la concordia entre los hombres y satisfacen tanto sus anhelos físicos como los espirituales.

Quizás sea un tanto desacertado afirmar tajantemente que con Invocaciones y con el descubrimiento de la mitología empieza la madurez de Cernuda. Primero, porque tal descubrimiento ocurre, como el propio autor confiesa, «más que mediada la colección», de modo que su influencia no alcanza $a$ priori a todos los textos. Segundo, porque existe cierta controversia al respecto: mientras que autores como Harris se refieren a este «momento de la transición del poeta a la madurez» (1992: 25), otros sostienen que Invocaciones es, más bien, la culminación de la etapa juvenil del poeta hispalense (Teruel, 2013: 35), y que dicha etapa concluye con «el ulterior entronque con la tradición romántica (Bécquer, Nerval, Hölderlin, etc.)» (Maristany, 1970: 11), apreciable también en la segunda fase, aunque en esta ya se produzca «la progresiva asimilación de la poesía anglosajona»².

Lo cierto es que ambas posturas tienen fundamento y, en el fondo, no son contradictorias, sino más bien complementarias. Por un lado, está justificado pensar que Invocaciones, más que el principio de la etapa madura, constituye el final de la juvenil: al fin y al cabo, la primera edición de La Realidad y el Deseo, de 1936, concluía con los poemas de Invocaciones, de modo que parecía formar una unidad - una progresión - con las colecciones anteriores, sin duda pertenecientes a su etapa más temprana. Así, Teruel (2013:37) considerará que es en Las nubes cuando Cernuda, llegado al trivio del que habló T. S. Eliot - la elección entre la autorrepetición, la renovación o el silencio - , abogó por «la tentativa de readaptar su poesía a un nuevo estado de conciencia», un estado marcado principalmente por dos factores: «el exilio y la entrada en la madurez vital». Por tanto, aunque sea en Invocaciones donde brillen los primeros síntomas de madurez ${ }^{3}$, seguramente es en Las nubes donde se consolidan y cobran forma definitiva, sobre todo a raíz de las antedichas circunstancias biográficas.

2 Muy similar es la propuesta de Paz (1965: 176) o de Ferrer (1997: 14-15).

3 Quizás sea preciso aclarar, para evitar malentendidos, que no estamos considerando que obras como Un río, un amor, Los placeres prohibidos o Donde habite el olvido sean obras inmaduras; más bien, pretendemos demostrar que se adscriben a una etapa de juventud en la que ciertas técnicas poéticas y ciertas concepciones de la realidad aún no habían sido ensayadas. 
Por otra parte, hay que tener en cuenta que, con el paganismo que toma de Hölderlin, Cernuda alcanza un hito crucial en su trayectoria literaria: la dicotomía que, hasta entonces, había articulado casi todos sus versos y que incluso había dado nombre a su obra poética completa - dato nada trivial se ha visto disuelta. Por fin, la realidad ha dejado de ser un entorno adverso para el florecimiento del deseo: ahora, el poeta ha encontrado un medio para comunicar su intimidad al mundo y lograr que encaje en él. El redescubrimiento de los dioses antiguos otorga sentido a la realidad mundanal y, a la vez, reaviva la hermosa chispa divina - como dijera Schiller - que los siglos habían apagado. Una palabra clave que definiría este nuevo estado sería armonía: la armonía entre el poeta y la naturaleza, entre el espíritu y el cuerpo, entre la poesía y la realidad. Esta idea también la subraya Harris (1992: 100) cuando se refiere a «la integración en la armonía cósmica».

Eso sí, el precio que el poeta debe pagar por este logro no es otro que el de la soledad, una condición que presenta aspectos negativos y positivos a la vez: negativos, porque es consabida la aflicción que la marginación conlleva; positivos, porque tal marginación permite conocer mejor el mundo y a uno mismo. El poeta debe sacrificar su existencia humana para alcanzar su plenitud como creador: la solitud y el dolor conducen a la clarividencia poética. Tal sacrificio también se aprecia en el «Himno a la tristeza»: «Viven y mueren a solas los poetas». Una vez más, nos hallamos frente al «viejo mito romántico, tan perceptible en la relación entre su vida y su obra, de que todo lo que perjudica al hombre beneficia al creador» (Teruel, 2013: 36). Como afirma Ruiz Silva (1979: 58), Cernuda encuentra «la posibilidad de entablar una relación biográfico-literaria que asume su autoconciencia de poeta maldito e incomprendido como Hölderlin».

Para Cernuda, la mitología no solo supone una vía de escape que lo aleja de la vileza humana sino que, al mismo tiempo, es también un punto de vista que permite embellecer el mundo y mejorarlo: ahí radica la reconciliación. El poeta se ubica, por consiguiente, en una «soledad activa, a la que el desprecio de los hombres lo ha empujado y que es concebida como una especie de atalaya desde la que luchar por un mundo mejor» (Teruel, 2013: 36).

Este distanciamiento permite que el poeta contemple el mundo con una mayor objetividad. Después de todo, la imparcialidad no se encuentra en el centro del canon, sino que tan solo es posible en la periferia, en los márgenes. 
En otras palabras: la verdad universal no se halla en uno mismo, sino en la visión del mundo desde fuera de él. La soledad se convierte, por consiguiente, en el emplazamiento idóneo para la óptima apreciación de la realidad. El hispalense incluso se sirve, en «Soliloquio del farero», de un recurso que aún no conocía porque no había leído a Robert Browning: el monólogo dramático, tan útil a la hora de separar la voz poética y el poeta de carne y hueso (Teruel, 2013: 38).

«Importa que el poeta se dé cuenta de cuándo acaba una fase y comienza otra en su desarrollo espiritual», asevera Cernuda (2000: 396). Con el descubrimiento de Hölderlin y la mitología griega, supera los patéticos lamentos por la incompatibilidad entre él y su ambiente, por la imposible libertad de su amor. También queda atrás el superrealismo francés, que «canalizó la expresión del mundo personal de Cernuda» (Maristany, 1970: 13) pero no el mundo ajeno a él; lo mismo ocurre con la «cosmovisión romántica» (Teruel, 2013: 35) de Donde habite el olvido: el dramatismo exacerbado desaparece. En Invocaciones priman la armonía y el equilibrio, fundamentales en su nueva concepción de la realidad.

La soledad no será lo único que modificará la perspectiva de Cernuda, sino también un aspecto crucial en esta nueva etapa: el poeta recibe una calidad de semidiós. Por un lado, no puede olvidar su naturaleza humana y sufrir como el hombre que es; por otro, no obstante, se sacrifica por el resto de la raza y vela por su bienestar, como queda patente en «Soliloquio del farero»:

Y erguido desde cuna vigilante

Soy en la noche un diamante que gira advirtiendo a los hombres.

Por quienes vivo, aun cuando no los vea;

Y así, lejos de ellos,

Ya olvidados sus nombres, los amo en muchedumbres.

El monólogo dramático de esta composición permite que la voz poética, encarnada en el personaje del farero, se desvincule de la subjetividad de Cernuda y adquiera los rasgos de aquel que dirige la luz del faro: aislado en su retiro espiritual, alejado de los hombres pero siempre protegiéndolos con su luz desde lo alto. 
Así pues, la figura del poeta oscila entre la del hombre de carne y hueso y la del dios olímpico: aquejado por sus pesares, sí, pero capaz de abstraerse de ellos. Según Gariano (1965: 241), «tal unción sacerdotal, a la manera pagana, es el galardón que consuela al poeta a cambio de los fugaces honores mundanos y fortalece en la conciencia de pertenecer a un mundo superior».

Pero no son sus poderes ni sus atributos físicos los que confieren esta divinidad al artista, sino su visión: aunque es un hombre, mira al mundo con los ojos de un dios. Se trataría, por tanto, de la búsqueda de una realidad alternativa - mitológica o sobrehumana - por medio de una perspectiva nueva. En este sentido, recuerda a la visión angélica de R. M. Rilke ${ }^{4}$, a la que Cernuda se refiere en un estudio elaborado entre 1958 y $1959^{5}$ :

Según Rilke, el ser humano, la visión y el sentir humanos, son inadecuados en relación con los del ser angélico; pero al mismo tiempo reconocía que era posible sobrepasar dichas limitaciones humanas; el hombre debe esforzarse por ver como el ángel [...], habitando simultáneamente, lo mismo que el ángel, los dos mundos de lo visible y de lo invisible. (1971: 135)

Ambas concepciones son muy similares. Tanto los ángeles como las divinidades griegas gozan de esa sobrenaturalidad que tanto gusta a Cernuda a la hora de buscar una verdad alterna. De hecho, si sustituyéramos al ángel por el dios griego, este párrafo se adaptaría perfectamente a la poética de Hölderlin -y luego de Cernuda - que venimos explicando: el hombre debe olvidarse de su condición humana y contemplar la naturaleza con los ojos de una deidad.

El hecho de que el poeta, como semidiós, también forme parte de esta dimensión mitológica otorga aún más coherencia a la concepción hölderliniana y cernudiana: los mitos que pueblan secretamente la yerma realidad terrenal no son sino consecuencia de la mirada del poeta. Es él quien los crea y, a la vez, quien los descubre más allá de la apariencia mundana.

4 Casualidad o no, Hans Gebser había escrito un libro acerca de Rilke y su estancia en tierras españolas: Rilke und Spanien (Zúrich, 1946).

5 La fecha en que Cernuda redacta estas líneas es muy posterior a la publicación de Invocaciones; no obstante, el propio poeta confiesa haber sentido hacia Rilke «una de esas filiaciones entrañables, uno de esos estímulos profundos, que nos son tanto más queridos y necesarios cuanto más extraño y hostil se nos vuelve el mundo en torno» (1971: 132). Es muy probable que el sevillano hubiera descubierto a Rilke cuando empezó a leer a Hölderlin, o sea, cuando a mitad de los años 30 se interesó por la poesía alemana. 
Respecto de la concepción del poeta como ser ambivalente, conviene recordar cómo caracteriza Cernuda a Hölderlin en la nota previa a su traducción:

Algunos hombres, en diferentes siglos, parecen guardar una pálida nostalgia por la desaparición de aquellos dioses [...]. Son tales hombres imborrable eco vivo de las fuerzas paganas hoy hundidas, como si en ellos ardiese todavía una chispa de tan armoniosa hoguera religiosa [...]. Y la misma dramática aptitud [...] convierte a esos seres mortales en seres semidivinos perdidos entre la confusa masa de los humanos. Tal fue el caso de Friedrich Hölderlin. (1935: 115-116)

En este extracto no solo se recalca la propuesta de la divinidad oculta que alberga el poeta, sino otra idea clave del pensamiento de Cernuda: aquellos dioses griegos, tan dignos de elogio y devoción, han muerto. La antigua civilización griega desapareció y, con ella, sus mitos y sus valores. Lo único que queda del paganismo es un eco tenue que, de vez en cuando, alguna mente iluminada es capaz de recoger: así lo hizo Hölderlin y, siglo y medio después, también Cernuda. Esta cualidad excepcional, claro está, convierte a quienes la poseen en seres extraordinarios.

A continuación, conviene que examinemos el paganismo cernudiano de manera diacrónica: no únicamente en Invocaciones, sino también en obras anteriores y posteriores. Efectivamente, la influencia de la mitología de Hölderlin no se da únicamente en el mentado poemario, sino que es más bien el resultado de un germen que crece a lo largo de La Realidad y el Deseo, alcanza su culmen con la lectura del romántico alemán y finalmente decae en las últimas colecciones.

Lo cierto es que Cernuda consolida - y no descubre - esta concepción pagana del mundo: no se trata de un pensamiento nuevo para el sevillano, sino la confirmación de un punto de vista que él ya había esbozado en sus poemas y reflexiones anteriores. De la misma opinión es Harris (1992: 102-103):

La idea de una realidad superior, cuya definición se elabora en Invocaciones, es una extensión de la visión de la naturaleza elemental en Los placeres prohibidos, con la adición ahora de una dimensión casi religiosa que la acerca al panteísmo. [...] Pero su declaración [...] indica que Cernuda, más que someterse a una influencia, había encontrado un espíritu afín al suyo que le ayudaría a clarificar las actitudes que estaban en gestación antes del 
encuentro. La influencia de Hölderlin viene a ser una confirmación de una línea temática ya emprendida.

Seguidamente, Harris (1992: 101-104) espiga algún ejemplo que demuestra cómo Cernuda, en poemarios anteriores, ya había coqueteado con la visión mitológica del planeta y de la vida. En opinión del estudioso, tal sería el caso del poema III de Donde habite el olvido («Esperé un dios en mis días / Para crear mi vida a su imagen»), que aparece transfigurado en Invocaciones de la siguiente manera: «La soledad poblé de seres a mi imagen / Como un dios aburrido». Al parecer, el hombre que buscaba un dios con el que llenar su vida ha acabado convirtiéndose en él y dando vida a otros seres, lo cual nos remite a la condición semidivina del poeta.

No obstante, el verdadero anticipo de la poética hölderliniana se da en dos casos: en «De qué país» (Los placeres prohibidos) y en «Los fantasmas del deseo» (Donde habite el olvido). En la primera composición, la voz poética contempla cómo «dioses y diosas olvidados / Levantan brazos inexistentes o miradas marmóreas» (como en «A las estatuas de los dioses»); la conclusión manifiesta la imposibilidad de alcanzar el mundo divino: «No podrás [...] / vivir aquellas realidades que te gritan con lengua inagotable. / Deja, deja, harapiento de estrellas; / Muérete bien a tiempo».

En «Los fantasmas del deseo», el poeta se dirige a la naturaleza y exalta su divina belleza, olvidada por el hombre: «Tierra, tierra y deseo. / Una forma perdida». De hecho, es significativo que esta composición no aparezca numerada - a diferencia de la precedente serie de dieciséis poemas - , sino destacada claramente con título propio. A juzgar por este dato y por el contenido del texto, parece tratarse más bien de un epílogo que se despide de Bécquer, o un prólogo que saluda a Hölderlin.

En este colofón de Donde habite el olvido, ya se aprecia la visión panteísta que definirá el mundo natural recreado en el poemario consecutivo. Es más, existen sugerentes conexiones entre «Los fantasmas del deseo»y algunos poemas de Invocaciones: el «alentar pagano» de la tierra, «el mar esbelto», el rubio mancebo de apariencia casi mitológica o la idea de que la tierra es la madre de toda belleza y, por tanto, la única diosa a la que quiere adorar. 
Después de Invocaciones, la cosmovisión pagana seguirá presente en Las nubes, aunque con menos vigor. Encontraremos aún los «desnudos cuerpos» de los «radiantes mancebos» idealizados a la manera griega («A un poeta muerto»), la visión de la naturaleza desde una perspectiva panteísta («Jardín antiguo $\left.»^{6}\right)$, la idea de que la soledad está reservada para el poeta-semidiós o «hijo desnudo y deslumbrante del divino pensamiento» («A Larra con unas violetas») y la imagen de la estatua como símbolo del dios olvidado («Resaca en Sansueña»). En este último poema, la parte II se titula «Monólogo de la estatua» y recuerda al colofón de Invocaciones: «A las estatuas de los dioses». En ambas composiciones se crea una atmósfera de melancolía por las desaparecidas deidades griegas, condenadas al frío y al abandono del mármol. Pero en el «Monólogo de la estatua» algo ha cambiado:

Pero los pueblos mueren y sus templos perecen,

Vacíos con el tiempo el cielo y el infierno

Igual que las ruinas. Vinieron nuevos dioses

A poblar el afán temeroso del hombre.

Como ocurre con todo, las religiones también caducan y ceden el trono a otras. En Las nubes, Cernuda es más consciente de la decadencia de los dioses antiguos y de lo inútil y anacrónico que es creer en ellos. Su fe simbólica en la mitología griega comienza a tambalearse con el paso de los años, sobre todo porque es consciente de que ya no es tan joven como antes y ha perdido el tiempo cantando a «eternos dioses sordos», como los llamará en Como quien espera el alba.

De hecho, Cernuda volverá a hablar con Dios en Las nubes: en «La visita de Dios», una voz poética preocupada por la edad («Pasada se halla ahora la mitad de mi vida») se dirige a la divinidad cristiana y parece volver a creer en su existencia, por mucho que la increpe e interrogue. Citamos el siguiente fragmento por su sugerente ambigüedad:

Pero a ti, Dios, ¿con qué te aplacaremos?

Mi sed eras tú, tú fuiste mi amor perdido,

[...]. Levantados de naipes,

Uno tras otro iban cayendo mis pobres paraísos.

6 En esta composición, Cernuda parece volver la vista atrás y evocar, por medio de la naturaleza, «la espina aguda del deseo» $y$ «la juventud pasada», ambas concebidas como el «sueño de un dios sin tiempo». Es un planteamiento que recuerda considerablemente al de Invocaciones. 
¿Cuáles son los «pobres paraísos» del poeta? Podríamos aventurar la hipótesis de que tales paraísos son los espacios sagrados en los que Cernuda, fugazmente, ha sido feliz: tal vez, la infancia; tal vez, el deseo; y, también tal vez, la mitología pagana. Los dioses antiguos han caído como un castillo de naipes; ahora, Dios vuelve a figurar, de un modo u otro, en los versos del sevillano ${ }^{7}$. Es lógico que las religiones vayan cayendo, una tras otra, en el ciclo implacable que caracteriza al universo: como afirmó el propio Hölderlin, «el helenismo y el cristianismo no son más que momentos históricos de un mismo proceso evolutivo de la humanidad» (1977: 20).

El paganismo proseguirá su paulatino declive en obras posteriores, tal como anota Harris (1992: 108): en Como quien espera el alba apenas encontraremos cuatro poemas referidos a los dioses paganos o al mundo clásico («El águila», «Las ruinas», «Ofrenda» $\mathrm{y}$ «Urania»). En el primero, los hombres aparecen como «bufones ilustres de los dioses»: tal es el desengaño. En el segundo, el poeta, harto de «perseguir eternos dioses sordos», se dirige desesperadamente a Dios y lo declara inexistente. En el tercero, en cambio, regresa efímeramente la fe en los dioses y en sus valores hedónicos. En el cuarto, la voz poética alaba las cualidades de Urania, musa griega de la astronomía. Y, después de estos cuatro poemas que abren Como quien espera el alba, Cernuda no vuelve a recuperar el motivo mitológico de forma tan significativa en toda la colección.

Tampoco lo hará en el resto de su obra. Dos únicas excepciones pueden salvarse: «Las edades», en Vivir sin estar viviendo, y «El elegido», en Con las horas contadas. En el primero, el declive pagano aparece una vez más simbolizado por las estatuas de los dioses antiguos en los museos. El siguiente extracto habla por sí solo:

La piedra cariada, el mármol corroído,

Es descomposición del dios, segura

De consumarse bajo el aire, como

Bajo la tierra la del hombre;

Ambos, el dios y el hombre, iguales

7 También se lo mencionará en «Atardecer en la catedral», en «Tristeza del recuerdo» y en «Cementerio en la ciudad», entre otros poemas, y estará implícito en «Lázaro» y en «La adoración de los magos», puesto que ambos proceden de episodios bíblicos. Por breves que sean las alusiones, delatan que Dios vuelve a estar presente en el pensamiento de Cernuda, en sustitución del panteón helénico. 
Ante el ultraje igual del azar y del tiempo

Cuyo poder los rige, y aceptada

La humildad de perderse en el olvido.

La situación ha sido revertida con el paso del tiempo: si en Invocaciones era el poeta el que recibía cualidades divinas, en Vivir sin estar viviendo son los dioses quienes padecen los estragos humanos. Como los hombres, los dioses son seres caducos que sucumben a los siglos y que se desvanecen cuando nadie cree en ellos.

En cuanto al segundo poema, «El elegido», es el «único poema posterior que sostiene algo de la fe en los dioses» $\mathrm{y}$ «alude a un muchacho sacrificado a los dioses aztecas para preservar eternamente su belleza» (Harris, 1992: 108.). Es una muestra más de paganismo, aunque este sea de raigambre precolombina y no helénica.

Si hemos estudiado esta progresión, ha sido para demostrar que la de Hölderlin no fue una influencia esporádica ni una cosmovisión pasajera: fue la confirmación de un planteamiento que ya había anclado sus raíces en Cernuda algún tiempo atrás y que necesitaba un estímulo para florecer. Tal estímulo fue la poesía del alemán, que no hizo sino detonar unas ideas que estaban a punto de estallar.

La afirmación de Haro Ibars (1975: 64) de que «la diferencia entre el alemán [Hölderlin] y el sevillano [Cernuda] estriba en que el primero cree en los dioses, y el segundo los añora. [...] Todo lo que en él queda de Grecia son estatuas rotas, héroes muertos» resulta a todas luces insuficiente. Cernuda también atraviesa una etapa, como hemos comprobado, en la que su fe en los dioses griegos es manifiesta, aunque sea cierto que, en la evolución que acabamos de reflejar, el sevillano pase de adorar las cualidades del panteón pagano a mirar con lástima las patéticas estatuas divinas.

Y no solo eso: el mismo desengaño gradual se aprecia en Hölderlin, quien durante tantos años y tantos versos alabó los valores helénicos y creyó en los dioses olímpicos («Grecia», «A Hércules», «Aquiles», «Dioses han pasado antes», «Los dioses», etc.), pero al final proclamó su inevitable desencanto. Dicha desilusión sobrevino entre 1800 y 1801, en la época de las grandes elegías, y coincidió con la etapa de madurez en que el alemán comenzó a entrever su fracaso: se había ganado la antipatía de Goethe y Schiller, buen amigo 
de Hölderlin, había cortado su correspondencia con él y no le había ayudado a conseguir el puesto de profesor auxiliar de griego en la Universidad de Jena. Aparte de las dificultades pecuniarias que atravesaba Hölderlin, cabe añadir que «pocos años le quedaban antes de que su razón naufragase» (Cernuda, 1971: 77). En lo tocante a la poesía, es en sus grandes elegías donde el poeta expresa su visión de Grecia en términos mucho más desalentadores y nostálgicos:

Di, ¿dónde está Atenas? Tu ciudad amada,

oh dios enlutado. ¿Convertida en polvo [...]?

$¿$ No queda un vestigio que en el navegante que pasa

la evoque, recuerde su nombre? ¿No es allá donde se alzaban las columnas y sobre los techos veíanse fulgurar las estatuas de los dioses? («El archipiélago»)

En esta extensa elegía, el germano evoca los tiempos de grandeza de los dioses pero reconoce, muy a su pesar, que nada queda de ellos, ni siquiera un atisbo de fe en los corazones de los hombres. Los tiempos han cambiado y el espíritu humano ya no es el mismo de antes. Federico Gorbea recoge una sentencia clave del alemán: «los dioses mueren cuando el entusiasmo muere» (1977: 18-19).

Sin embargo, que los dioses griegos existan o no - o que todavía conciten o no devoción - es lo menos relevante. Para Cernuda, al igual que para Hölderlin, «lo que los dioses representan es más importante de lo que son en sí mismos», señala Harris (1992: 108). Suscribimos su tesis de que, «al igual que en el caso de Hölderlin, los dioses para el poeta sevillano son el símbolo de un juicio de valor al que ha llegado con respecto al mundo en que vive». Efectivamente, lo significativo del paganismo en Cernuda y Hölderlin no es que los dioses griegos todavía gobiernen los cielos, sino que representan un modelo de vida preferible a aquel que proponen el cristianismo y la sociedad moderna. El descubrimiento de la mitología entraña una nueva mirada hacia el mundo, dispuesta a reformarlo.

Es preciso recalcar que el caso de Hölderlin fue muy semejante, tal como explica Gasó Gómez (2013: 14):

No podemos olvidar que Las grandes elegías y los himnos del suabo giran en torno al deseo de revivir las tradiciones de la Grecia clásica, a la que él 
anhelaba ver resurgir en su propio país [...], como una necesidad de materializar todo el bagaje mitológico en el mundo real. Tal vez la obra más representativa de este anhelo implícito sea Hiperión, en cuya estructura epistolar se presenta a un joven griego que lucha por aprovechar la gloria de su pueblo para fomentar un renacimiento cultural.

Como Cernuda, el germano se sirve de los mitos para distanciarse de la realidad y ser capaz de mejorarla desde la objetividad, desde la soledad del poeta marginado. Al fin y al cabo, el joven Hiperión no deja de ser, a la manera del monólogo dramático, la figura tras la que se esconde el afán regeneracionista y benefactor del propio Hölderlin.

Ese mismo afán será heredado por Cernuda, de la mano de la misma mitología helénica. Cuando el hispalense ya ha afianzado esta nueva perspectiva, los dioses antiguos dejan de resultarle necesarios y los abandona en sus poemas - no así en su subconsciente-: «los dioses desaparecen de su poesía después de haberle otorgado esa visión clarificada, pero legándole a su vez los valores espirituales que representan y que van a proporcionar el telón de fondo a toda la poesía de su época madura» (Harris, 1992: 109). En otras palabras: Grecia y Hölderlin podrán haberse desvanecido de la obra de Cernuda, pero no su manera de mirar la realidad.

\section{REFERENCIAS BIBLIOGRÁFICAS}

BRuton (1984), Kevin J., «Luis Cernuda's debt to Hölderlin», en Revue de Littérature Comparée, 58, págs. 37-49.

Cernuda, Luis y GebSer, Hans (1935), «Hölderlin», en Cruz y Raya, 32, págs. 113-134.

Cernuda, Luis (1970), Crítica, ensayos y evocaciones, edición de Luis Maristany, Barcelona, Seix Barral, 1970.

- Poesía y literatura I y II (1971), Barcelona, Seix Barral.

- (2000), La Realidad y el Deseo (1924-1962), Madrid, Alianza.

FERrer, Anacleto (1997), Hölderlin en la lírica española del siglo Xx, Valencia, Episteme. 
Gariano, Carmelo (1965), «Aspectos clásicos de la poesía de Luis Cernuda», en Hispania, 48, 2, págs. 234-246.

Gasó GómEZ, Nuria (2013), «Friedrich Hölderlin en la obra de Luis Cernuda», en Repositorio Digital de la UPF. En línea: https:/ / repositori.upf.edu/bitstream/handle/ 10230/22099/TFG_Gaso\%20Nuria.pdf?sequence=1\&isAllowed=y. Último acceso el 18-dic-2018.

Gorbea, Federico (1977), «Prólogo» a Friedrich Hölderlin, Hölderlin. Poesía completa (edición bilingüe), Barcelona, Ediciones 29, págs. 13-22.

Haro Ibars, Eduardo (1975), «Cernuda en Hölderlin», en Triunfo, 29, 649, págs. 63-64.

Harris, Derek (1992), La poesía de Luis Cernuda, Granada, Universidad de Granada.

HöLDERLIN, Friedrich (1974), Poemas, traducción de Luis Cernuda y Hans Gebser, edición de Jenaro Talens, Madrid, Visor.

- (1977), Hölderlin. Poesía completa (edición bilingüe), traducción de Federico Gorbea, edición de Alfredo Llorente Díez, Barcelona, Ediciones 29.

MARISTANY, Luis (1970), «Prólogo y notas» a Luis Cernuda, Crítica, ensayos y evocaciones, Barcelona, Seix Barral, págs. 7-31.

OTERo, Carlos-Peregrín (2004), «Cernuda y el romanticismo: el hombre y su demonio», en Nuria Martínez de Castilla y James Valender (eds.), 100 años de Luis Cernuda, Madrid, Publicaciones de la Residencia de Estudiantes, págs. 369-395.

PAz, Octavio (1965), Cuadrivio, México, Joaquín Mortiz.

Pujante, David (2004), «Luis Cernuda, traductor de Hölderlin», en Revista electrónica de estudios filológicos, 7. En línea: www.um.es/tonosdigital/znum7/ portada/ monotonos/cernuda42.htm. Último acceso el 18-mar-2018.

Ruiz Silva, Carlos (1979), Arte, amor y otras soledades en Luis Cernuda, Madrid, Ediciones de la Torre.

Teruel, José (2013), Los años norteamericanos de Luis Cernuda, Valencia, Pre-textos. 


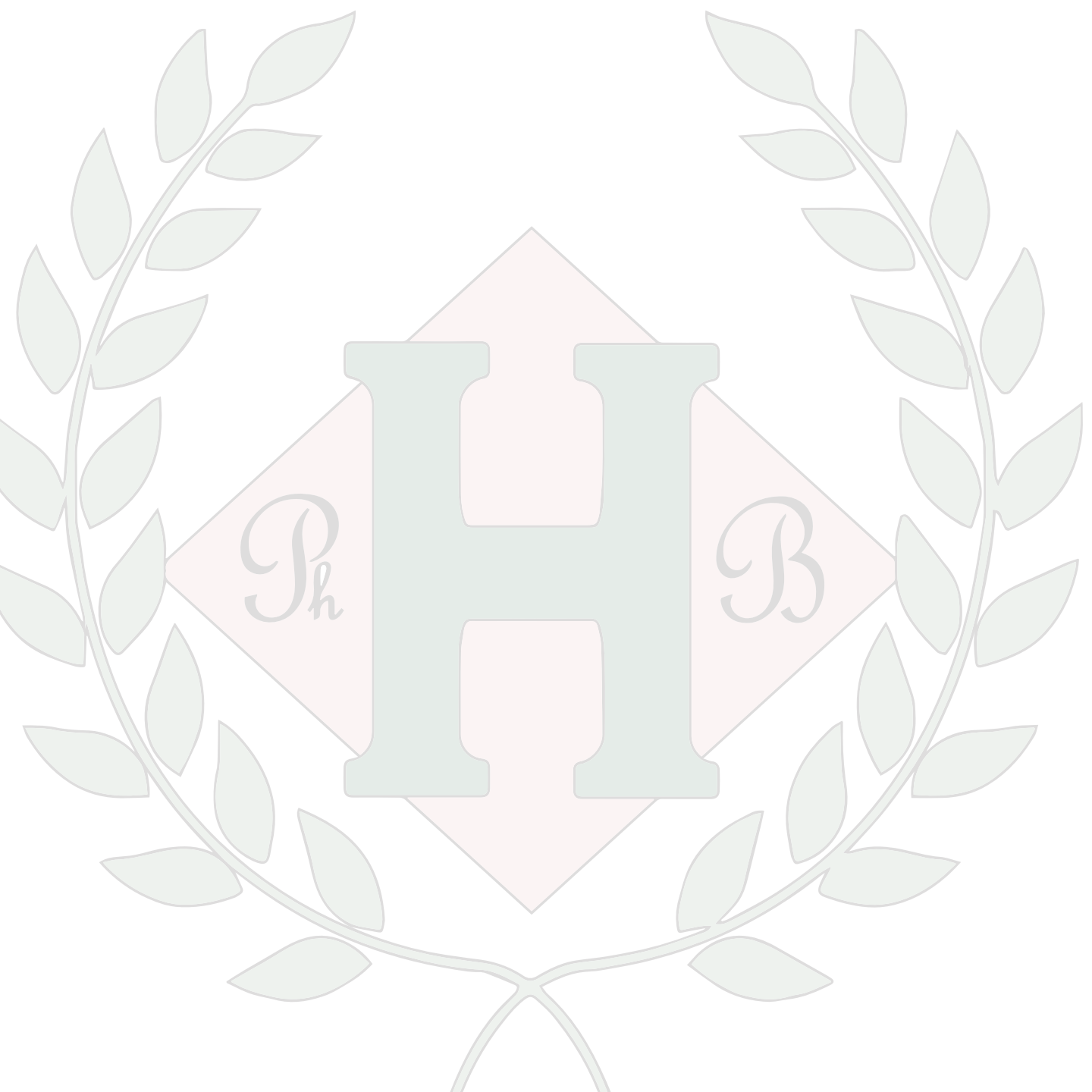

